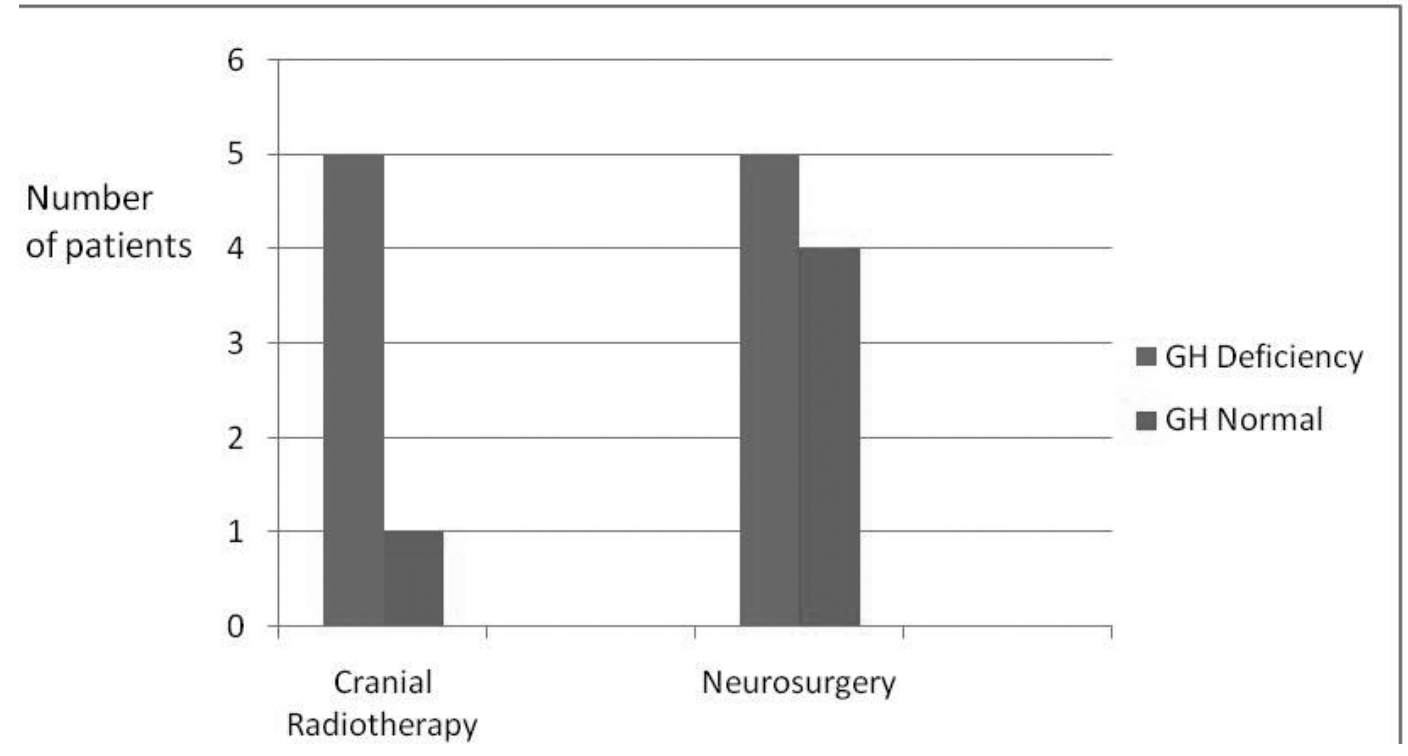

Abstract G180(P) Graph 1 Growth Hormone Status relative to radiotherapy/neurosurgery

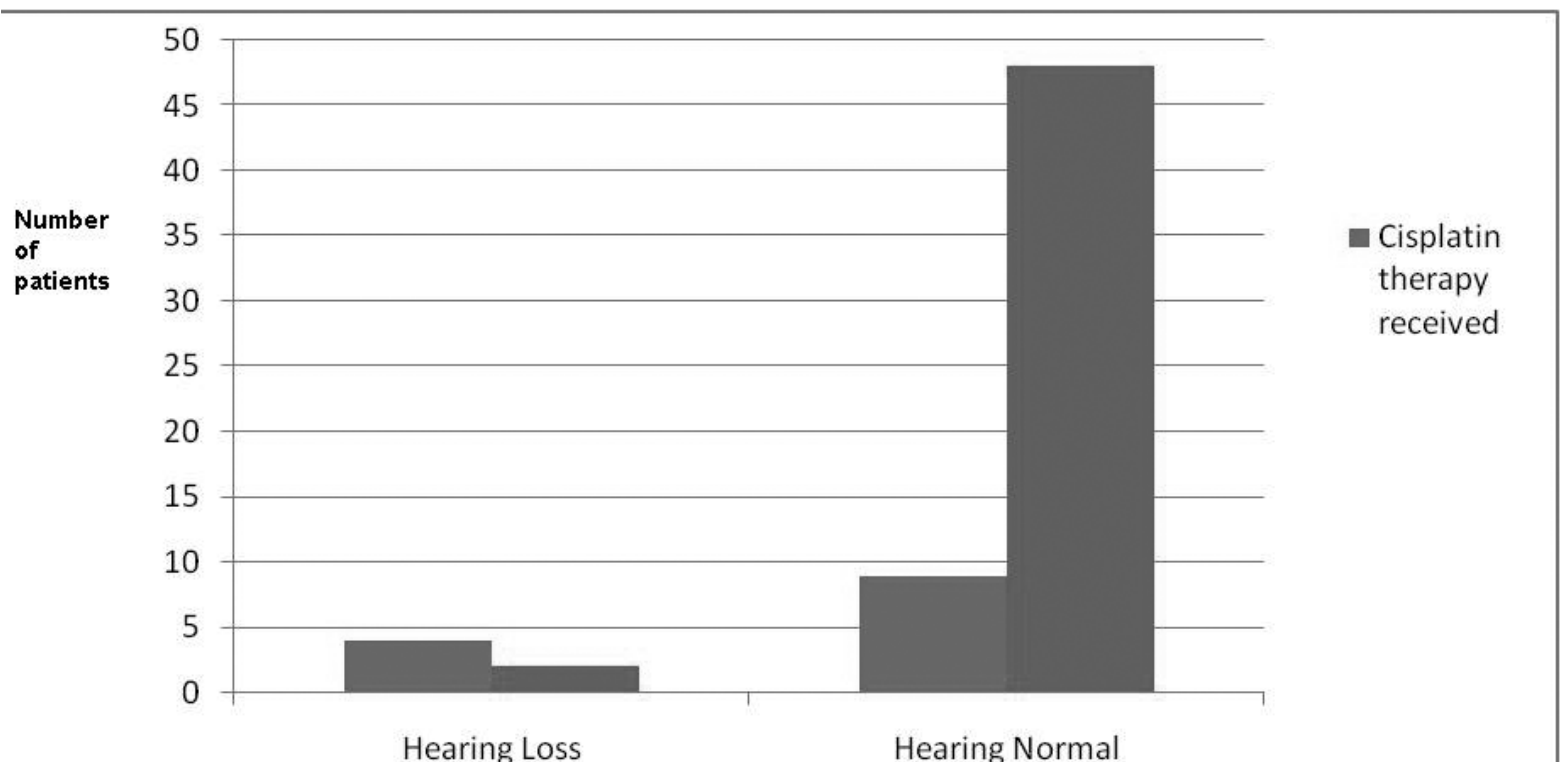

Abstract G180(P) Graph 2 Hearing loss and Cisplatin Therapy

fertility $(17 \%)$, renal $(13 \%)$, respiratory $(8 \%)$, cardiac $(6 \%)$ and other endocrine effects (8\%). The late effects were chiefly diagnosed by the hospital-based Late Effects clinic (63\%), primary care $(13 \%)$ and other secondary care clinicians (9\%).

Conclusion This study found that the prevalence of cancer treatment related late effects in adult survivors of childhood cancer was high. The Late Effects clinic was the principle route by which late effects were diagnosed. Early detection of late effects is of critical importance in optimising the long-term health of cancer survivors however there is a drive to reduce hospital-based follow-up of cancer survivors due to high patient demand. Our retrospective analysis suggests that primary care based follow-up is not currently sufficiently developed to detect these late effects. This study did not compare the Late Effects clinic to other methods of follow-up or include analysis of economic data; these areas should be addressed in future work.

\section{G182(P) AUDIT OF EFFICIENCY OF BLOOD PRODUCT TRANSFUSION IN LEVEL 2 POSCU}

doi:10.1136/archdischild-2013-304107.194

G Popli, Z Ataullah, A Kumar, S Thompson. Paediatrics, UHNS NHS Trust, Stoke-onTrent, UK

Aims Review efficiency and adequacy of blood and platelet transfusions in paediatric malignancy and haemoglobinopathy patients, based on recommendations from BCSH 2009, UK standards for children with thalassemia 2008 and local trust guidance.

Methods We retrospectively reviewed 80 blood and platelet transfusions in 10 children during August 2011- June 2012. 60 occurred in 7 children with malignancy (34 Red cell and 26 Platelets), and 20 red cell transfusions in 3 children with beta thalassemia major. We used as thresholds, a low $\mathrm{Hb}$. $8 \mathrm{~g} \%$, maximum $\mathrm{Hb}$. of $12 \mathrm{~g} \%$ and a 
correction factor of 3; for platelets, counts of 20-30 or as specified ie $>50$ post neurosurgery, or $>75$ for LP; and for thalassemia $\mathrm{Hb} .>9 \mathrm{~g} \%$. We also used as an estimate volume in a Red cell unit as $270 \mathrm{mls}$ and platelet unit as $180 \mathrm{mls}$, unless specified.

\section{Results}

\section{Appropriate in time:}

Thalassemia: 20/20 Red cell transfusions were all elective and in routine hours.

Haem-Onc.: 40/60 were elective of which $34 / 40$ occurred in routine hours. 18/60 were "pragmatic" ie. in anticipation of chemo, procedures, sepsis, discharge etc., of which $7 / 18$ occurred in routine hours. 2/60 were urgent transfusions, occurred in routine hours.

Appropriate in amount:

The weights across all 10 patients ranged from $8-49 \mathrm{~kg}$.

\section{Abstract G182(P) Table 1}

\begin{tabular}{lllll}
\hline Patient Group & & Mean & Median & Range \\
\hline Haem-Onc. Red cell & Pre transfusion Hb (G\%) & 7.6 & 8 & $4.6-8.5$ \\
transfusions & Volume $(\mathrm{ml} / \mathrm{kg})$ & 11.9 & 12 & $5.5-20$ \\
& Post transfusion Hb (G\%) & 10.9 & 11.2 & $8.2-13$ \\
Haem-Onc. Platelets & Pre transfusion count & 38.5 & 40.5 & $14-56$ \\
& Volume (ml/kg) & 7 & 4.1 & $3.8-16.7$ \\
Thalassemia Red cell & Post transfusion count & 85 & 68 & $52-388$ \\
transfusions & Pre transfusion (G\%) & 9.1 & 9.1 & $8.3-11$ \\
& Volume transfused $(\mathrm{ml} / \mathrm{kg})$ & 17.1 & 17.6 & $14-23$ \\
\hline
\end{tabular}

Conclusions $85 \%$ elective and $40 \%$ pragmatic transfusions occurred in routine hours. Pre transfusion thresholds and volume of transfusions in all 3 groups were acceptable. The variation in prescribed volumes reflects minimising exposure and wastage by prescribing in units wherever possible. These correlations are best visualised on the attached slides.

\section{G183(P) COST EFFECTIVENESS OF HYDROXYUREA THERAPY IN PREVENTING INPATIENT ADMISSIONS DUE TO VASO- OCCLUSIVE CRISIS IN SICKLE CELL CHILDREN - A DISTRICT GENERAL HOSPITAL EXPERIENCE}

doi:10.1136/archdischild-2013-304107.195

S Ramprakash, E Roantree, K Willis. Department of Paediatrics, Luton and Dunstable Hospital, Luton, UK

Aim To study the effectiveness of hydroxyurea in reducing the number of inpatient admissions due to vaso-occlusive crisis in children with sickle cell disease and estimation of potential cost savings for the NHS.

Methods Retrospective audit of number of admissions, length of stay, use of intravenous opioids over a period of 2 years before and after starting hydroxyurea treatment in 5 children with sickle cell disease.

Results Of 5 patients with sickle cell disease 3 with HbSS and 2 with $\mathrm{HbSC}$ were started on hydroxyurea over the last 5 year period. Comparison was made between the numbers, severity and duration of the vaso-occlusive episodes needing inpatient admission before and during treatment are made and potential cost savings for the NHS estimated.

After starting treatment with hydroxyurea there was a reduction in the number of inpatient admission by $38 \%$ (50 vs 31) and inpatient days by $43 \%(184 \mathrm{Vs} 105)$. A reduction in proportion of admissions needing iv opioids (20\% Vs $12.9 \%$ ) as well as in the number of inpatient days on iv opioids (29 days vs 9 days, reduction by $69 \%$ ). In one patient the treatment was stopped after 11 months due to poor compliance with blood tests. All patients showed decrease in the number of admissions and opioid use except for one patient in whom there was an apparent increase in both. The diagnosis was revised as sickle cell with fibromyalgia syndrome and hydroxyurea was later discontinued without increase in pain symptoms.

Total cost of hydroxyurea treatment over 2 year period for the 5 patients was $£ 3602$. There was a reduction in number of high dependency admission by 20 days and non-high dependency admission day by 60 . The total potential cost saving from reduced admission was $£ 73220$. Net savings for the NHS estimated over the 2 years since starting hydroxyurea for the above 5 patients was $£ 69618$.

Conclusion Commencing hydroxyurea treatment after careful patient selection in sickle cell children with frequent vaso-occlusive crisis can achieve significant cost savings for the NHS while improving the quality of patient care.

\section{G184(P) THROMBOPHILIA TESTING IN CHILDREN; THREE CASE VIGNETTES}

doi:10.1136/archdischild-2013-304107.196

AD Danaee, JA Alamelu. Department of Haematology, Guys and St Thomas' Hospital, London, UK

Aim An increasing number of children are being tested for inherited thrombophilias. We present three cases of children known to our centre, who were tested for and found to have a positive thrombophilia test to illustrate the wide spectrum of issues and challenges that can arise and the implications for the children, their families and the health care professionals involved in their care.

Methods In most children a combination of risk factors lead to the development of symptomatic VTEs, and idiopathic VTEs, unlike in the adult population are extremely rare.

Thrombophilia testing in children with a proven VTE, is controversial, and at present there are no guidelines for thromboprophylaxis in children with heritable thrombophilia. Even more challenging is testing children who are asymptomatic. Clearly the family history of the inherited thrombophilia is relevant, but also of importance is the knowledge that any genetic testing should be done with the purpose of improving outcome for the individual concerned.

Results The three chosen examples are children aged between 2 and 16. The first case is a young girl with an extensive family history of childhood thrombosis in her father and uncle, who has inherited the same protein $\mathrm{C}$ mutation but is asymptomatic herself, the second is a young boy with a family history of protein $\mathrm{S}$ deficiency who was diagnosed with a PE and found to have the same mutation. And the third is a young boy who was tested inadvertently but was found to have antithrombin deficiency.

Conclusions These are only three examples from our haemostasis $\&$ thrombosis centre chosen to illustrate some of the challenges that arise in testing children for inherited thrombophilias and their longterm management and follow up. There is very little information available with regards to thrombophilia testing in asymptomatic children, which highlights even more so the importance of ensuring that the child and their family are reviewed by specialists in coagulation medicine and the decision to test for inherited thrombophilia is made based on the information obtained in the history, relevant to that child with appropriate counselling prior to testing and with a knowledge of the limitations of thrombophilia testing.

\section{G185(P) FEVER AND BACTERIAL INFECTIONS IN CHILDREN WITH SICKLE CELL DISEASE}

doi:10.1136/archdischild-2013-304107.197

B Morrissey, T Bycroft, 0 Wilkey, J Daniels. Paediatrics Department, North Middlesex University Hospital, London, UK

Background and aims Children with sickle cell disease (SCD) are at an increased risk of developing bacteraemia and other serious bacterial infections, which can be associated with significant morbidity and mortality. Fever, however, is a common symptom in children with 